\title{
Cross-coupling Reaction of $\beta, \beta$-Difluoro- $\alpha$-phenylvinylstannane with Alkenyl Iodides: Novel Approach to 2-Phenyl-1,1-difluoro-1,3-butadienes
}

\author{
Ji Hoon Choi, Kamaldeep Paul, Yeon Hui Jung, and In Howa Jeong* \\ Department of Chemistry and Medical Chemistry, Yonsei University, Wonju 220-710, Korea. *E-mail: jeongih@yonsei.ac.kr \\ Received August 6, 2009, Accepted November 6, 2009
}

Key Words: Cross-coupling reaction, $\beta, \beta$-Difluoro- $\alpha$-phenylvinylstannane, Alkenyl iodides, 2-Phenyl-1,1difluoro-1,3-butadienes

\begin{abstract}
1,3-Butadienes have received much attention because they are valuable synthetic intermediates for the formation of carbocyclic and multifunctionalized system in organic synthesis. ${ }^{1}$ Especially, 1,1-difluoro-1,3-butadienes are useful building blocks for the introduction of difluoromethylene $\left(\mathrm{CF}_{2}\right)$ and monofluoromethylene $(\mathrm{CFH})$ unit into organic molecules. ${ }^{2-5}$ However, there are only limited reports on the synthesis of 1,1-difluorinated 1,3-butadienes which were prepared mainly via the $\beta$-defluorination, dehalogenation and Wittig reactions. Huang et al. prepared 1,1-difluoro-2-siloxy-1,3-butadiene from the reaction of trifluoroacetyltriphenylsilane with vinylmagnesium bromide followed by a sequence Brook rearrangement of triphenylsilyl group and $\beta$-defluorination. ${ }^{6} \mathrm{Mg}(0)$-Promoted selective $\mathrm{C}$-F bond cleavage of trifluoromethyl enones afforded 1-methoxy-4,4-difluoro-3-(trimethylsiloxy)-1,3-butadienes. ${ }^{5}$ Double dehydrobromination of 1,3-dibromo-1,1-difluoro com-
\end{abstract} pounds with DBU afforded 1,1-difluoro-1,3-butadienes. ${ }^{7} \mathrm{We}$ also reported the preparation of 2,3-disubstituted 1,1-difluoro1,3-butadienes via 1,4-debromofluorination reaction. ${ }^{8,9}$ Wittig reaction of 3,3-difluoroallyltriphenylphosphonium bromide with aldehydes also gave 1,1-difluoro-1,3-butadienes. ${ }^{10} 1,1$-Difluoro-4,4-bis(dimethylamino)-1,3-butadienes were synthesized from the treatment of 1,1-difluoro-4,4-bis(dimethylamino)ethane with ethyl propiolate. ${ }^{11}$ However, we are interested in the straightforward method for the synthesis of 1,1-difluoro1,3-butadienes from the cross-coupling reaction of 2,2-difluoroalkenylmetal reagent with alkenyl halides, which should be a simple and efficient method. Palladium-catalyzed crosscoupling reactions of 1,1-difluorohomoallenyl bromide with aryl bromides and iodides and aryl boronic acids provided the corresponding 1,1-difluoro-1,3-butadienes. ${ }^{12}$ Ichikawa et al. prepared 1,1-difluoro-1,3-butadienes from the reaction of 2,2difluorovinylboranes with 1-alkenyl halides in the presence of copper(I) iodide and a palladium catalyst. ${ }^{13}$ The use of 2,2difluorovinylzinc reagent ${ }^{14}$ as a coupling partner also gave the 1,1-difluoro-1,3-butadienes. Recently, Burton et al. reported that 1,1-difluoro-1,3-butadienes were prepared from the Sonogashira type of coupling reactions of $\alpha$-bromo- $\beta, \beta$-difluorostyrenes with vinylboronic acid in the presence of Pd catalyst. ${ }^{15}$ However, the previous methods have main drawbacks such as the use of unisolable vinylmetal reagents in solution, moisture sensitivity and lack of generality. Herein, we wish to report first preparation of 1,1-difluoro-2-phenyl-1,3-butadienes via the direct coupling reaction of the thermostable and isolable $\beta, \beta$ - difluoro- $\alpha$-phenylvinylstannane with alkenyl iodides in the presence of $\mathrm{Pd}$ and $\mathrm{CuI}$ catalyst.

Recently, we reported a novel method for the synthesis of $\beta, \beta$-difluoro- $\alpha$-phenylvinylstannane 1 and its coupling reaction with aryl iodides in the presence of catalyst to give 2,2-diaryl1,1-difluoroethenes. ${ }^{16}$ In the course our studies on the coupling reaction of 1 , we examined the reactivity of carbon-carbon bond formation between 1 and alkenyl halides to afford 2-phenyl1,1-difluoro-1,3-butadienes (Table 1). When 1 was treated with 1.1 equiv of 1,1-difluoro-2-iodo-2-phenylethene in refluxing THF for 4 hours in the presence of $\mathrm{Pd}\left(\mathrm{PPh}_{3}\right)_{4}(10 \mathrm{~mol} \%)$ and $\mathrm{CuI}(10 \mathrm{~mol} \%)$, unreacted starting material 1 was recovered (entry 1). When the same reaction was performed in DMF at $80{ }^{\circ} \mathrm{C}$ for 2 hours, however, the desired diene $2 \mathbf{a}$ was obtained in $38 \%$ yield (entry 2 ). The use of 2.2 equiv of 1 ,1-difluoro-2iodo-2-phenylethene under the same reaction condition resulted in the formation of the desired product $2 \mathbf{a}$ in $73 \%$ yield (entry 4). The same reaction was performed at $50{ }^{\circ} \mathrm{C}$ for 5 hours, but no reaction occurred. The reaction at $100{ }^{\circ} \mathrm{C}$ resulted in the decomposition of all reagents and no desired product was obtained. Increase of equivalence of 1,1-difluoro-2-iodo-2phenylethene caused to decrease the formation of product $\mathbf{2 a}$ dramatically. We also tried the reaction between 1 and 2-bromo1,1-difluoro-2-phenylethene under the optimized reaction con-

Table 1. Optimization for the coupling reaction between 1 and 1,1difluoro-2-iodo-2-phenylethene

\begin{tabular}{cccccc}
\multicolumn{5}{c}{$\overbrace{\mathrm{SnBu}_{3}}$} \\
Entry & $\mathrm{X}$ (equiv) & Solvent & $\mathrm{T}\left({ }^{\circ} \mathrm{C}\right)$ & $\mathrm{t}$ (hours) & Yield $(\%)^{a}$ \\
\hline 1 & 1.1 & $\mathrm{THF}$ & reflux & 4 & 0 \\
2 & 1.1 & $\mathrm{DMF}$ & 80 & 2 & 38 \\
3 & 2.2 & $\mathrm{THF}$ & reflux & 4 & 0 \\
4 & 2.2 & $\mathrm{DMF}$ & 80 & 2 & 73 \\
5 & 2.2 & $\mathrm{DMF}$ & 100 & 1 & - \\
6 & 2.2 & $\mathrm{DMF}$ & 50 & 5 & 0 \\
7 & 3.0 & $\mathrm{DMF}$ & 80 & 1 & 55 \\
8 & 4.0 & $\mathrm{DMF}$ & 80 & 1 & 15 \\
9 & 6.0 & $\mathrm{DMF}$ & 80 & 1 & $<5$ \\
\hline
\end{tabular}

${ }^{a}$ Isolated yield. ${ }^{b}$ All reagents were decomposed. 
Table 2. Preparation of fluorinated 1,3-dienes 2 via the coupling reactions of $\mathbf{1}$ with various types of alkenyl iodides

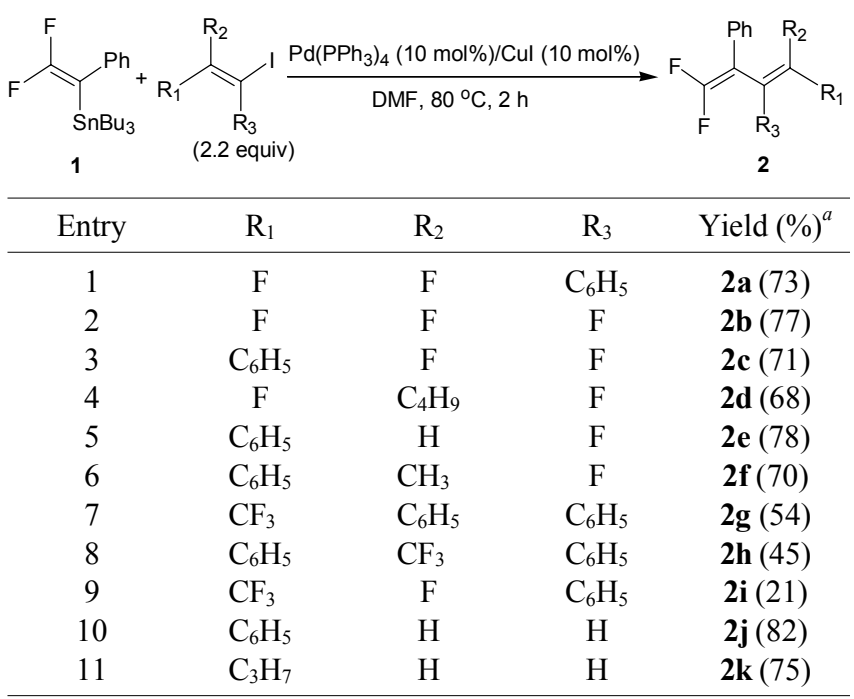

${ }^{a}$ Isolated yield.

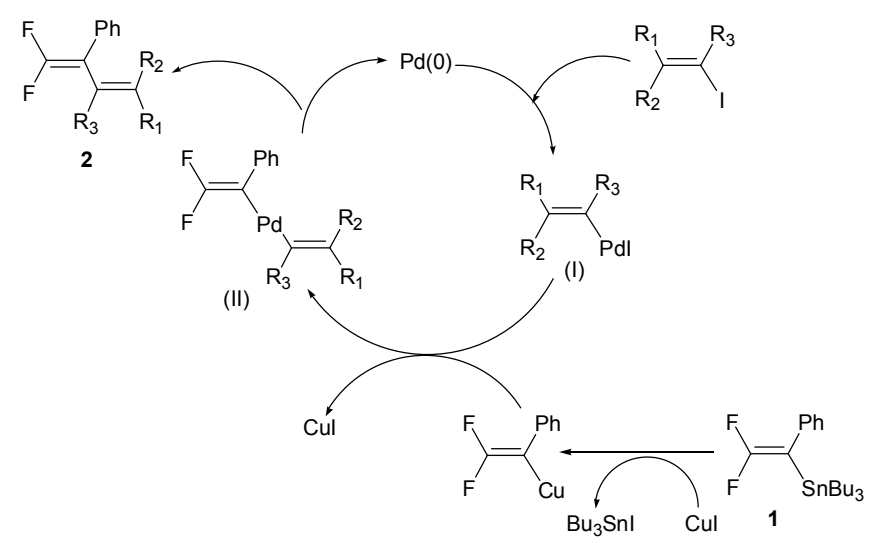

Scheme 1. A proposed mechanism for the coupling reactions of $\mathbf{1}$ with alkenyl iodides

dition, but the desired product 2a was obtained in $27 \%$ yield.

The reactions of 1 with a various types of alkenyl iodides in DMF at $80{ }^{\circ} \mathrm{C}$ for 2 hours in the presence of $\mathrm{Pd}\left(\mathrm{PPh}_{3}\right)_{4}(10$ $\mathrm{mol} \%)$ and $\mathrm{CuI}(10 \mathrm{~mol} \%)$ gave the corresponding 1,3-butadienes $\mathbf{2 b - 2 k}$ in $21-82 \%$ yields (Table 2). It seems likely that the coupling reaction was not influenced by the steric effect of substituent attached to reactive vinyl carbon site (entry 1). On the other hand, electronic and steric effect caused by trifluoromethyl group $\left(\mathrm{CF}_{3}\right)$ at $\beta$-vinyl carbon was a main factor for the decrease of yield of the coupling products 2 (entry 7-9) Alkenyl iodides having proton, fluoro, phenyl and alkyl substituent at $\alpha$ or $\beta$ position of reacive vinyl carbon afforded the corresponding 1,3-butadienes $\mathbf{2}$ in high yields (entry 2-6, 10, 11).

Although the reaction mechanism of coupling reaction of 1 with alkenyl iodides is not clear, we assume that intermediate (I) formed by oxidative addition reaction of alkenyl iodides with $\mathrm{Pd}\left(\mathrm{PPh}_{3}\right)_{4}$ reacts with $\beta, \beta$-difluoro- $\alpha$-phenylvinylcopper, generated from the reaction of $\mathbf{1}$ with $\mathrm{CuI}$, to give an intermediate (II) which undergoes reductive elimination to produce the 1,3-butadienes 2 (Scheme 1). Although role of $\mathrm{CuI}$ in the coupling reaction is obscure, it was suggested that copper iodide facilitates the transmetallation step in the cross-coupling mechanism cycle and thus speeds the cross-coupling in the presence of Pd catalyst. ${ }^{17}$ One experimental result showed that the decomposition of $\mathbf{1}$ was observed from the reaction of $\mathbf{1}$ with the same equivalent of $\mathrm{CuI}$ only, which indicates that vinylcopper reagent was formed.

A typical reaction procedure for the preparation of $\mathbf{2 a}$ is as follows. A $15 \mathrm{~mL}$ two-neck round bottom flask equipped with a reflux condenser, a magnetic stirrer bar, a septum and argon tee connected to an argon source was charged with $\beta, \beta$-difluoro- $\alpha$ phenylvinylstannane $(0.100 \mathrm{~g}, 0.230 \mathrm{mmol}), 1,1$-difluoro-2iodo-2-phenylethene $(0.136 \mathrm{~g}, 0.510 \mathrm{mmol})$ and $5 \mathrm{~mL}$ DMF. After $\mathrm{Pd}\left(\mathrm{PPh}_{3}\right)_{4}(0.023 \mathrm{mmol})$ and $\mathrm{CuI}(0.023 \mathrm{mmol})$ were added, the mixture was heated at $80{ }^{\circ} \mathrm{C}$ for 2 hours and then quenched with water. The reaction mixture was extracted with diethyl ether $(30 \mathrm{~mL} \times 2)$. The diethyl ether solution was dried with anhydrous $\mathrm{MgSO}_{4}$, filtered, and concentrated under reduced pressure. The residue was purified by silica gel column chromatography. Elution with $n$-hexane and EtOAc $(20: 1)$ provided $0.047 \mathrm{~g}$ of $\mathbf{2 a}$ in $73 \%$ yield. $2 \mathrm{a}$ : oil: ${ }^{1} \mathrm{H}$ NMR (400 $\left.\mathrm{MHz}, \mathrm{CDCl}_{3}\right) \delta$ 7.37-7.30 (m, 4H), 7.28-7.20 (m, 6H); ${ }^{13} \mathrm{C} \mathrm{NMR}$ $\left(100 \mathrm{MHz}, \mathrm{CDCl}_{3}\right) \delta 154.7(\mathrm{t}, J=294.8 \mathrm{~Hz}), 129.6,128.6,128.4$, $127.7,127.5,88.5(\mathrm{dd}, J=20.6,15.5 \mathrm{~Hz}) ;{ }^{19} \mathrm{~F}$ NMR $(376 \mathrm{MHz}$, $\mathrm{CDCl}_{3}$, internal standard $\left.\mathrm{CFCl}_{3}\right) \delta-82.45(\mathrm{~d}, 2 \mathrm{~F}, J=24.8 \mathrm{~Hz})$, $-86.36(\mathrm{~d}, 2 \mathrm{~F}, J=24.8 \mathrm{~Hz}) ; \mathrm{MS} m / z$ (relative intensity) $278\left(\mathrm{M}^{+}\right.$, 100), 258 (40), 238 (42), 227 (33), 209 (30), 178 (16), 151 (37), 127 (80), 119 (28); Anal. Calcd for $\mathrm{C}_{16} \mathrm{H}_{10} \mathrm{~F}_{4}$ : C, 69.07; H, 3.62 . Found: C, 68.94; H, 3.60 .

Acknowledgments. This work was supported by the Basic Research Grant (2009-0073839) funded by the National Research Foundation of Korea.

\section{References}

1. Carruthers, W. Cycloaddition Reactions in Organic Synthesis; Pergamon: Oxford, 1990.

2. Matsuo, N.; Kende, A. S. J. Org. Chem. 1988, 53, 2304-2308.

3. Jin, F.; Xu, Y.; Huang, W. J. Chem. Soc. Chem. Commun. 1993, 814-816.

4. Jin, F.; Xu. Y.; Huang, W. J. Fluorine Chem. 1995, 71, 1-4.

5. Amii, H.; Kobayashi, T.; Terasawa, H.; Uneyama, K. Org. Lett. 2001, 3, 3103-3105.

6. Jin, F.; Xu, Y.; Huang, W. J. Chem. Soc. Perkin Trans. 1 1993, 795-800.

7. Elsheimer, S.; Foti, C. J.; Bartberger, M. D. J. Org. Chem. 1996, 61, 6252-6255.

8. Jeong, I. H.; Park, Y. S.; Chung, M. W.; Kim, B. T. Synth. Commun. 2001, 31, 2261-2270.

9. Son, J. B.; Cho, J. A.; Choi, J. H.; Jeong, I. H. Bull Korean Chem. Soc. 2008, 29, 31-32.

10. Qiu, W.; Burton, D. J. J. Fluorine Chem. 1993, 65, 143-147.

11. Xu, Y.; Tian, F.; Dolbier, W. R., Jr. J. Org. Chem. 1999, 64, 55995602.

12. Shen, Q.; Hammond, G. B. Org. Lett. 2001, 3, 2213-2215.

13. Ichikawa, J.; Ikeura, C.; Minami, T. Synlett 1992, 739-740.

14. Tellier, F.; Sauvetre, R.; Normant, J.-F. J. Organomet. Chem. 1986, 303, 309-315.

15. Raghavanpillai, A.; Burton, D. J. J. Org. Chem. 2006, 71, 194-201.

16. Choi, J. H.; Jeong, I. H. Tetrahedron Lett. 2008, 49, 952-955.

17. Behling, J. R.; Babiak, K. A.; Ng, J. S.; Campbell, A. L. J. Am. Chem. Soc. 1988, 110, 2641-2643. 